\title{
crianças e música: educação musical e estudos da infância em diálogo
}

\author{
sandra mara da cunha ${ }^{1}$ \\ universidade do estado de santa catarina, brasil \\ orcid id: http:/ / orcid.org/0000-0002-2952-1796
}

resumo

A relação entre crianças e música é a temática sobre a qual se debruça este artigo concebido em caráter de ensaio, com o objetivo de pensar uma educação musical da infância. Seus fundamentos teóricos se encontram nas conversações entre a educação musical e os estudos da infância e nortearam a oficina-palestra realizada no II Congresso de Estudos da Infância, em setembro de 2019, na Universidade do Estado do Rio de Janeiro. O texto aborda as aberturas presentes em abordagens criativas que adotam currículos que irão se constituir no decorrer dos processos de ensino e aprendizagem musical, como os que têm o formato em rede e círculos. Improvisações e composições feitas por crianças, orientadas por professores-artistas que conhecem seu ofício, emergem dessas dinâmicas experimentais. Ao mesmo tempo, a participação das crianças e a atuação colaborativa junto a seus professores conferem novos sentidos ao papel docente com o exercício da dupla escuta: das crianças e de suas expressões musicais, no que chamo de músicas das crianças. $\mathrm{O}$ desenvolvimento de pesquisas com crianças em contextos nos quais as abordagens musicais criativas são a marca de aulas e cursos nessa área reafirma também a importância das divulgações e discussões acerca dos seus contributos, que se voltam tanto para a educação musical como para o campo da educação, e também para os estudos da infância, visto que ouvir o fazer musical das crianças possibilita saber mais sobre o que pensam, sentem e fazem quando criam suas músicas. Uma maior visibilidade e audibilidade para as músicas inventadas por elas e o reconhecimento da importância da educação musical na escola podem vir como resultados alvissareiros.

palavras-chave: educação musical; estudos da infância; abordagens criativas; dupla escuta.

\section{children and music: musical education and childhood studies in dialogue}

abstract

Children and music are the theme of this article conceived as a sort of rehearsal, with the aim of thinking a musical education of childhood. Its theoretical foundations emerge from conversations between music education and childhood studies, and formed the basis for the lecture workshop held at the II Congress of Childhood Studies, in September 2019, at the University of the State of Rio de Janeiro. The text addresses methodological openings present in creative approaches to curricula based on network formats and circles. Improvisations and compositions made by children and guided by professor-artists who know their craft, emerge from these experimental dynamics. The participation of children in collaborative action with their teachers gives, in turn, new meanings to the teacher's role in the form of "double listening" - listening both to children and to their musical expressions. The development of research in children's music has powerful implications both for musical education and for the field of education. This research also contributes to childhood studies, since listening to children's musical expressions makes it possible to know more about what they think, feel and do when they create their music. It also

\footnotetext{
1 E-mail: cunhasandramarada@gmail.com
} 
promises to result in greater visibility and audibility for the songs invented by them, and for the recognition of the importance of music education in schools.

key words: music education; childhood studies; creative approaches; double listening.

$$
\text { niños y música: educación musical y estudios de la infancia en dialogo }
$$

resumen

Los niños y niñas y la música es el tema que aborda este artículo concebido como un ensayo, con el objetivo de pensar una educación musical de la infancia. Sus fundamentos teóricos se encuentran en las charlas entre la educación musical y los estudios de la infancia y guiada según el taller de conferencias celebrado en el II Congreso de Estudios de la Infancia en septiembre de 2019 en la Universidad Estatal de Río de Janeiro. El texto aborda las aperturas presentes en los enfoques creativos que adoptan planes de estudio que constituirán en el curso de los procesos de enseñanza y aprendizaje musical, como los que tienen formato de red y círculos. Improvisaciones y composiciones realizadas por niñas y niños, guiadas por profesores-artistas que conocen su oficio, surgen de estas dinámicas experimentales. La participación de los niños y niñas y la acción colaborativa con sus profesores, a su vez, dan nuevos significados al papel docente con el ejercicio de la doble escucha: de los niños y de sus expresiones musicales, en lo que llamo músicas de niñas y niños. El desarrollo de la investigación con niñas y niños en contextos en los que los enfoques musicales creativos son la marca de las clases y cursos en esta área, también reafirman la importancia de las divulgaciones y discusiones sobre sus contribuciones, con sus aportes a la educación musical y al campo de la educación, y también para los estudios de la infancia, ya que escuchar la realización musical de niñas y niños hace posible saber más sobre lo que piensan, sienten y hacen cuando crean sus músicas. Una mayor visibilidad y audibilidad para las músicas inventadas por ellas y el reconocimiento de la importancia de la educación musical en la escuela, puede venir como resultados que sean bienvenidos.

palabras clave: educación musical; estudios de la infancia; enfoques creativos; doble escucha. 
crianças e música: educação musical e estudos da infância em diálogo

\section{para início de conversa}

A relação entre crianças e música é a temática sobre a qual este artigo se debruça, pensada com base no encontro da educação musical com os estudos da infância. Essas conversações interdisciplinares nortearam a oficina intitulada "crianças e música: diálogos da educação musical com os estudos da infância", realizada no II Congresso de Estudos da Infância, em setembro de 2019, na Universidade do Estado do Rio de Janeiro.

A oficina propôs aos participantes experiências de criação musical com o uso de materiais sonoros inusitados como sacolas plásticas, caixas de papelão e outros objetos garimpados em suas bolsas e mochilas. Guiados por cartões com imagens de obras vindas das artes visuais, cada grupo inventou sua interpretação sonoromusical para a partitura imagética. Ao optar por um caminho que privilegiou os sons desses instrumentos não convencionais como matéria prima em vez de ações organizativas com base em músicas já estabelecidas e conhecidas, a oficina ecoou o dizer de Kohan (2018, p. 299), porque o intuito foi o que atuassem “a partir da lógica da experiência e não a partir da lógica do saber ou do conhecimento". No final, conversamos sobre os fundamentos orientadores que resultaram na proposição da oficina, os quais foram também guias para a escrita desse texto.

Os contributos dos estudos da infância à educação musical e desta aos campos da educação e dos estudos da infância podem gerar debates interdisciplinares instigantes que levam a modificações nos modos de pensar as crianças e de atuar com elas. São trocas de saberes que se alimentam e se retroalimentam, ampliam conhecimentos, provocam rupturas, lançam desafios, reafirmam a ética como fundamento primeiro da docência na infância e apontam para o exercício de uma atitude educativa que nomeio como dupla escuta - das crianças e das músicas que elas inventam e reinventam.

Nesse caminho de escutas, adultos reconfiguram suas concepções de educação musical e de infância e são conclamados a reposicionar o lugar docente: de ensinadores de habilidades de tocar e cantar para o de acolhedores da 
curiosidade das crianças diante de instrumentos musicais e objetos que soam, e o de promotores de aprendizagens pela via dos processos de criação. Olafur Eliasson ${ }^{2}$ (apud Holm, 2007, p. 13) expressou bem qual seria esse novo papel docente pois, segundo ele, "para que a linguagem artística se desenvolva e aperfeiçoe, é preciso que haja um interlocutor qualificado". A atuação passa a se dar mais em consonância com as crianças, ao compreenderem que as infâncias que vivem são distintas face às suas pertenças de classe, raça, gênero e cultura, e que este fato impacta nas relações e nas escolhas pedagógicas.

A seguir alguns pressupostos vindos dos estudos da infância que me permitem articular conhecimento sobre infância e crianças para fundamentar minha atuação com elas, como professora de música, pesquisadora e orientadora.

\section{olhares e escutas para as crianças}

Os estudos da infância vêm se constituindo como campo multidisciplinar na somatória de olhares, pensares, escutas e pesquisas que objetivam compreender esse fenômeno complexo e heterogêneo chamado infância. Ao adotar novos paradigmas para pensar a infância, reconhecendo que as crianças podem falar em seu próprio nome e dizer de si, esses estudos promovem revisões da ação docente e ampliações do conhecimento acerca das crianças e seus contextos de vida, com investigações que vêm sendo realizadas não apenas sobre elas, mas também com a participação delas.

Prout (2005), ao fazer uma retrospectiva do caminho tomado pela sociologia da infância para se constituir como campo de conhecimento que adotou o estatuto da infância como construção histórico-social e a geração como sua principal categoria de análise, propôs um redirecionamento na condução desses estudos, tendo em vista as mudanças ocorridas na sociedade ao longo dos anos e as pesquisas já realizadas na área. Se, num primeiro momento, aquele do estabelecimento do campo, o aspecto social era fundamental e contraposto ao

\footnotetext{
2 Para saber conhecer a obra e o pensamento do artista visual Olafur Eliasson, acessar: https://olafureliasson.net/archive/artwork.
} 
aspecto individual e biológico da infância, o futuro, segundo o autor, aponta para um diálogo entre esses dois aspectos.

Para ele, a sociologia da infância, na urgência de dar prioridade ao aspecto social nas suas investigações, foi deixando pelo caminho importantes questões ligadas ao fator biológico da infância. Por isso, no momento em que o sociólogo fez a revisão de seus próprios escritos, argumentou ser necessário recuar um pouco e recolher o que foi deixado para trás:

[...] os estudos da infância descrevem uma trajetória que envolve a dicotomia natureza-cultura e operou dentro de um pensamento modernista que separou natureza e cultura, ziguezagueou entre os polos dessa oposição, ora colocando a infância na sua vertente biológica, ora colocando-a na vertente social.

[...] O futuro dos estudos sobre a infância repousa em encontrarmos maneiras de tratar a infância como "natureza-cultura". Somente pelo entendimento das maneiras nas quais a infância é construída pelos elementos heterogêneos da cultura e da natureza, o que em muitos casos não podem ser facilmente separados, é que será possível fazer o campo avançar (Prout, 2005, p. 44, tradução livre).

Os estudos da infância apontam na direção das integrações de áreas e do compartilhamento dos saberes, e não das dicotomias que caracterizaram o mundo contemporâneo, herdeiro direto do modernismo. Ainda de acordo com Prout (2005, p. 2, tradução livre, grifos meus):

A infância é mais bem estudada quando não se restringe a ser colocada dentro de uma moldura construída a partir da assunção implícita de uma série de dicotomias opostas. Isso caracteriza muitos dos novos estudos sociais sobre a infância, porque ela é tratada como uma construção social. Esta visão social é contraposta a uma visão natural ou biológica. Desse ponto de vista eles são o reverso do discurso que se coloca em uma relação opositora às visões mais antigas, as ideias biológicas sobre a infância. A infância não é e nunca foi um fenômeno puramente social. As relações sociais são heterogêneas, são feitas de uma profunda variação de recursos materiais, discursivos, culturais, naturais, tecnológicos, humanos e não humanos. A infância, assim como todos os fenômenos, é heterogênea, complexa e emergente, e, por causa disso, seu entendimento requer um amplo aparato de recursos intelectuais, uma aproximação interdisciplinar e um processo investigativo de mente aberta.

Assim é que, por exemplo na questão do desenvolvimento das crianças, ao mesmo tempo em que não pode ser deixado de lado quando as estudamos, não pode mais ser colocado como característico apenas da infância. Todos os seres 
humanos, em todas as etapas de suas vidas, estão se desenvolvendo; ninguém parece estar pronto, em qualquer que seja o aspecto a ser observado e acompanhado ao longo do tempo, seja ele biológico ou cultural. No caso das crianças, seu desenvolvimento cognitivo pode ser entendido como qualidades de pensamento que devem ser consideradas, ao mesmo tempo em que entendemos também que não seguem um modelo de maturação biológica etapista que uniformiza todas elas, uma norma ou resposta padrão a ser esperada ou alcançada, como se fosse independente de suas pertenças sociais e culturais. $\mathrm{O}$ estudo do desenvolvimento do ser humano jovem rumo à vida adulta pode ser compreendido também com base em uma abordagem que se desloca do aspecto puramente individual, como se ele acontecesse em um vazio histórico, social e cultural, para uma abordagem holística na qual os contextos desempenham papel fundamental na constituição dos sujeitos. Para Rogoff, (apud Fidalgo, 2004, p. 8)

Uma das principais contribuições da Psicologia Cultural consiste exactamente em mostrar que não há "pessoas genéricas". Fala-se normalmente da "criança" como se tal entidade existisse em si mesma. "A criança" não existe enquanto tal - todas as crianças são históricas. Os seres humanos nunca estão sozinhos, mas em comunidades culturais com uma história, e nós não temos prestado atenção suficiente à forma como as pessoas participam nessas comunidades.

Membros jovens de sociedades e culturas distintas aprendem valores e estratégias que contribuem para a formação de suas identidades pessoais e sociais. Eles pertencem a comunidades, relacionam-se o tempo todo com adultos e com outras crianças, pelo menos em suas escolas, e por isso faz-se importante entendêlos não apenas como indivíduos ou seres em transição para a vida adulta, mas como participantes ativos dos grupos sociais aos quais pertencem. É o que Corsaro (2011, p. 128) nomeia como culturas de pares, termo que conceitua como "um conjunto estável de atividades ou rotinas, artefatos, valores e preocupações que as crianças produzem e compartilham em interação com as demais".

Em dois textos de sua autoria, Sarmento (2002; 2003), lançou a ideia de pensar a existência de uma gramática das culturas de pares infantis, que seriam como eixos que estruturam sentidos que elas compartilham entre si. Um desses eixos o autor denominou de "fantasia do real", e diz respeito ao modo de pensar das crianças, 
contraposto a um tipo de pensamento adulto, ocidental, e que se caracterizaria por ser instrumental, dirigido à racionalidade. Para o autor, as crianças não são ilógicas se as compararmos com adultos, mas lançam mão de outra lógica para pensar a identidade dos objetos que estão à sua volta. Por exemplo, nos seus jogos simbólicos, no brincar de faz de conta, as crianças usam objetos que ganham novas aplicabilidades, como grandes embalagens que viram casas, automóveis, barcos, e, em aulas de música podem funcionar como instrumentos musicais (Cunha, 2013). Esses objetos continuam sendo embalagens, com sua materialidade própria papelão, plástico, madeira, ao mesmo tempo em que são transformados em outras coisas e ganham novas funções pelo poder do imaginário infantil.

Pode-se observar, também, que crianças, apesar dessa capacidade imaginativa, mostram nos seus atos e falas que estão conscientes dessas transformações. Se estão imersas nesses mundos imaginários, brincando, quando são chamadas por seus pais ou cuidadores para se alimentarem ou saírem de casa, no mesmo instante saem desse lugar do faz de conta e retornam à cotidianidade de suas vidas. Elas possuem essa capacidade de habitar um mundo ao mesmo tempo real e imaginário, um mundo que se mistura, como se fora um parêntese, um entre mundos. Compreender o imaginário infantil a partir do que propõe a sociologia da infância coloca-se como fundamental, porque ele é constituinte de uma identidade infantil, um modo criança de se relacionar com o mundo que recém começaram a descobrir e explorar.

O imaginário infantil é inerente ao processo de formação e desenvolvimento da personalidade e racionalidade de cada criança concreta, mas isso acontece no contexto social e cultural que fornece as condições e as possibilidades desse processo. As condições sociais e culturais são heterogéneas, mas incidem perante uma condição infantil comum: a de uma geração desprovida de condições autónomas de sobrevivência e de crescimento e que está sob o controlo da geração adulta. A condição comum da infância tem a sua dimensão simbólica nas culturas da infância (Sarmento, 2003, p. 3).

O poder de imaginar e vivenciar o faz de conta, essa não literalidade, constitui-se como um elemento importante que, segundo Sarmento, "está na base da constituição da especificidade dos mundos infantis, e é um elemento central na capacidade de resistência que as crianças possuem face às situações dolorosas ou 
aviltantes da existência" (Sarmento, 2002, p. 16). Em conflitos provocados por guerras, nas grandes migrações, nas circunstâncias em que sofrem as agruras da pobreza, suspender a realidade e brincar de ser quem não são de verdade as ajuda a resistirem e manterem-se vivas.

A "reiteração", outro dos eixos de estruturação de sentido das culturas de pares infantis, de acordo com Sarmento (2002; 2003), refere-se à não linearidade temporal. O tempo das crianças é um tempo que prescinde de medições, que lhes permite o encontro entre presente, passado e futuro. Tempo recursivo, que pode ser sempre reiniciado, repetido. A reiteração nos diz dessa capacidade das crianças e do quanto elas gostam, por exemplo, de ouvir a mesma história ou de fazerem tudo de novo, e outra vez, e mais uma, ainda. A reiteração nos conta das misturas e fusões temporais que marcam os tempos da brincadeira e do sonho.

Kohan (2015, p. 225), pensa a infância para além dela enquanto grupo de idade - ou geração, e afirma que ela é modo de pensar e ser no mundo, "uma forma de tempo sensível", um tempo de viver que é também filosófico.

Um tempo antes do logos, um tempo afetivo, sentido. Outra vez, a infância chama à filosofia: philo-sophía, phílos: afeto, paixão, amizade. A filosofia é, como a infância, um tempo sensível, antes do logos, antes do tempo. Antes não significa necessariamente aqui, anterior na linha cronológica, significa um tempo primeiro, inicial, inaugural, uma condição. (Kohan, 2015, p. 225)

A capacidade infantil de habitar esse tempo-espaço híbrido é o lugar em que o encontro delas com o fazer artístico ganha em potência inventiva, novidadeira, porque a arte também opera nesse trânsito entre a imaginação e a sua concretização em objetos e fatos artísticos. Matérias primas como sons, imagens, movimentos e deslocamentos pelo espaço, cores e atos rotineiros perdem sua funcionalidade e podem ganhar significados outros quando usados em novos contextos e em situações inusitadas, como metáforas ou brincadeiras de faz de conta. A conexão infância-arte acontece o tempo todo em suas vidas, principalmente no caso das crianças pequenas e, talvez por isso, seja tão fácil para elas se manifestarem por meio das linguagens artísticas, que são também as linguagens da infância. Afinal, suas vozes falam por meio de desenhos, cenas, danças, músicas inventadas, e também 
pela quietude e pelo silêncio. A artista Shiota ${ }^{3}$, ilustra, a meu ver, essa conexão arteinfância. Em uma de suas instalações (Shiota, 2002) podemos ver um piano queimado envolto em uma rede de fios pretos; o piano perdeu sua função mas, segundo a artista, ainda assim ela conseguia ouvir seus sons, e afirmou: "Minha verdadeira palavra não tem som."

Para Schafer (1991, p. 290), a expressão artística das crianças pequenas é múltipla, fluida, híbrida. Ele sugere aos adultos que observem atentamente crianças pequenas em suas brincadeiras espontâneas e tentem, com isso, encontrar os limites entre as áreas artísticas, como nós, adultos, as definimos. Ele afirma, logo em seguida, que isso é "impossível" (Schafer, 1991, p. 290). São outras racionalidades, outras lógicas, ou, como disse Sarmento (2002, p.18), o lugar das crianças pode ser pensado também como "o lugar das culturas da infância".

Para professores no trabalho com a música, sejam especialistas ou não, tornase importante, portanto, levar em consideração como as crianças se apropriam ou não das propostas musicais lançadas por eles e como as reproduzem nas suas interações com as outras crianças, repetindo-as ou recriando-as. Aqui vamos encontrar também a expressão do pensamento e dos significados que as crianças atribuem ao que fazem, como ouvem o mundo e o expressam por meio de suas elaborações musicais. As etnografias nos trazem esse outro lado dos espaços educativos: o que as crianças pensam e fazem entre elas e que dizem de si mesmas (Lino, 2008; Cunha, 2018).

Em que lugar, então, cabem as crianças na educação musical? Ou, em outras palavras, qual lugar essa área de conhecimento as tem permitido ocupar? É sobre esse assunto que trata a próxima seção.

\section{por uma educação musical da infância}

Educação musical, território no qual habitam saberes e práticas as mais diversas sobre maneiras de ensinar e aprender música, é também campo de conhecimento que se constitui nas interseções entre a arte e a educação. Ao partir

\footnotetext{
3 Para saber sobre a artista Chiharu Shiota: https://www.chiharu-shiota.com/. Para visualizar a obra mencionada no texto: https://www.chiharu-shiota.com/in-silence-5
} 
do pressuposto de que música é atividade enraizada nas culturas humanas, podemos pensar que dentro da música existem muitas músicas e modos de fazê-las. Ao ensinar música, é importante considerar que "os processos e produtos culturais só podem ser compreendidos se considerados no seu contexto de produção sociocultural" (Arroyo, 2002, p. 19).

Diferentes sociedades e culturas praticam músicas e as ensinam de maneiras distintas, utilizando-se, para tanto, de propostas pedagógicas tão variadas quanto elas próprias. Em muitas culturas aprende-se por viver imerso em ambientes musicais, como no caso de grupos de prática de tradição oral; em outros aprendese por meio de mestres e especialistas, e existe, ainda, o aprender música de maneira autodidata. Muito do que se aprende sobre música(s), de modo sistematizado, acontece nos contextos formais das escolas e universidades, como é o caso da música ocidental, em gêneros como erudita e popular. Jorgensen (apud Arroyo, 2013, p. 231) esclarece que são legítimas todas essas maneiras de saber mais sobre música:

A educação musical [...] é uma colagem de crenças e práticas. Seu papel na formação e manutenção [dos mundos musicais] - cada qual com seus valores, normas, crenças e expectativas - implica formas diferentes nas quais ensino e aprendizagem são realizados. Compreender esta variedade sugere que pode haver inúmeras maneiras nas quais a educação pode ser conduzida com integridade. A busca por uma única teoria e prática de instrução musical aceita universalmente, pode levar a uma compreensão limitada.

Inspirada pela elucidação da filósofa, a educação musical que me afeta e me move na realização de pesquisas, e sobre a qual me proponho falar nesse texto, se coloca como crítica das relações de ensino-aprendizagem que são marcadas pela unilateralidade de um poder adulto - o adultocentrismo. Ela questiona a presença de modos de ensinar que centralizam decisões apenas nos professores, que escolhem caminhos pedagógicos nos quais as crianças não são enxergadas e muito menos ouvidas, e que não abrem espaço para elas exercerem a participação em seus percursos formativos nessa área artística. A participação infantil é pensada aqui como um dos direitos das crianças (Soares, 2005), situado nessa microrrealidade social chamada escola, e seu foco é o de pensar acerca do que diretamente lhes diz respeito, qual seja, o engajamento em seus percursos de aprendizagem musical, em qualquer que seja o contexto, na escola básica ou em outros espaços. 
Faço, nesse espaço, o exercício de pensar e defender uma educação musical da infância, não em um sentido de pequeneza e de pouca profundidade de conhecimento, mas de potência inventiva tal como as crianças têm me mostrado. As crianças me ensinaram muito sobre o quanto são capazes de se dedicarem exaustivamente ao que lhes afeta, ao que pode dizer delas mesmas. Comprometimento e introspecção, atitudes tão bem-vindas para a arte e para a educação, são provocadas pelos afetos. Afetos aqui pensados na perspectiva de Spinoza (2018, p. 98), como “afecções do corpo, pelas quais sua potência de agir é aumentada ou diminuída, estimulada ou refreada, e, ao mesmo tempo, as ideias dessas afecções".

Afetos, então, como ações que são mobilizadas pela atuação docente (Tadeu, 2002, p. 48). Nesse pensar uma educação musical da infância, o papel dos professores não é secundário, ele é crucial e a ser ressignificado para se colocar consonante com a dupla escuta.

Um professor que, antes de mais nada, tem horror à pedagogia da pergunta da resposta na manga. Um professor que não tem menos horror a uma pedagogia da solução de problemas. Em vez disso, um professor da pedagogia do problema que é a pedagogia do pensar. Mas não o pensar entendido como a boa conduta do raciocínio, como a regra do bem-pensar. Todo homem é mortal, etc. $\mathrm{O}$ princípio do terceiro excluído. Se A, então B. O cálculo das proposições. Falso e verdadeiro é igual a falso, etc. Nada disso. $\mathrm{O}$ pensamento, nessa pedagogia, tem pouco a ver com aquilo que já tem forma. Tem tudo a ver, por outro lado, com aquilo que, em uma zona que não é a da atualização, das coisas já determinadas e já formadas, faz saltar o impensável (Tadeu, 2002, p. 49).

E, para finalizar essa parte, não poderia deixar de lado o ensinamento de Freire (1996, p. 12), sobre a importância dos afetos, porque todos nós, professores e crianças, nos modificamos no desenrolar dos nossos encontros. Quando nossos percursos pedagógicos se aproximam de um fim que projetamos, olhamos para nós mesmos e percebemos que ganhamos novas formas, novos contornos.

É preciso que, [...], desde os começos do processo, vá ficando cada vez mais claro que, embora diferentes entre si, quem forma se forma e re-forma ao formar, e quem é formado forma-se e forma ao ser formado. É nesse sentido que ensinar não é transferir conhecimentos, conteúdos, nem formar é ação pela qual um sujeito criador dá forma, estilo ou alma a um corpo indeciso ou acomodado. 
Quais seriam então os marcadores dessa educação musical da infância que afeta as crianças e que lhes traz mais do que visibilidade, traz audibilidade para suas expressões musicais, resultantes de um conhecimento que já detêm e daqueles que se constroem em suas formações musicais em processo de constituição? Um jeito infantil de conceber a área que se abre às ideias de crianças e, com isso, as abordagens em educação musical conclamam um maior equilíbrio entre música, educação e infância.

Encontro um caminho, possível porque já experimentado no meu percurso de professora de música com crianças, ponto de partida (e, quiçá, ponto de chegada), nos percorridos por artistas não apenas da música, mas em todas as linguagens artísticas: as investigações de materiais e procedimentos, ideias, planos, imagens, temas que podem primeiro morar na imaginação, ou que aparecem em sonhos, nas sensações, que emergem da memória, e que resultam em criações, sejam elas efêmeras como improvisações, instalações e performances, ou mais permanentes como nas composições e arranjos. Essas últimas podem ensejar a necessidade de registros, como partituras ou gravações e filmagens. Penso então que as aulas de música ganhariam muito na aproximação rumo às crianças se puderem ser como ateliês de criação, nos quais professores-artistas assumem a postura de mestres que trabalham junto a seus aprendizes em ações e processos colaborativas, e que possam fazer música(s) desde o primeiro encontro.

A partir dessas considerações, trago fundamentos orientadores que caracterizam o pensamento e propostas pedagógicas de professores que são artistas e que são, portanto, conhecedores do seu ofício. São projetos e práticas pedagógicas que reconhecem como legítimas as estéticas resultantes das expressões infantis, assim como já acontece nas artes visuais.

As linguagens expressivas permitem às crianças simbolizarem suas sensações e sentimentos por meio de jogos construtivos sobre a matéria. Transformação construtiva que, em si, é ato estético, pois é essencialmente lúdico e poético ao envolver o prazer da sensorialidade. (Richter, 2012, p. 61)

No campo da educação musical, tais abordagens criativas emergiram mais fortemente alinhadas à estética da chamada música contemporânea, em meados do século XX. Incorporaram procedimentos dos músicos de vanguarda da época, que 
privilegiam a escuta ativa, a criação com ênfase no som e suas características, evitando a reprodução vocal e instrumental do que concebiam como música do passado. A adoção dos procedimentos elencados objetivava tornar os aprendizes mais aptos para ouvir e fazer música. A intenção era, e tem sido, desde então, a de trabalhar com base em atividades e propostas que levam a uma mais rápida assimilação de conceitos básicos e de elementos constituintes da linguagem, pela introdução dos alunos nas práticas musicais desde as primeiras aulas. Penso que, ao fazer essas escolhas, essas abordagens promovem uma aproximação em direção às crianças, como se os professores se desadultizassem porque passaram a levar em consideração tantos seus saberes como os contextos aos quais elas pertencem.

Uma mudança paradigmática acontece: ao invés da linearidade do conhecimento que se constrói por etapas que vão da mais fácil à mais elaborada, ou do básico ao avançado, indicam, a partir dos fundamentos mencionados, que o conhecimento pode ser construído em formatos como a rede, tal como propôs Paynter (1992). Assim procedendo, o ponto de partida pode ser em qualquer assunto da área, o qual, por sua vez, se conecta a outros tantos, e, na trama de saberes que vão se estruturando, a participação dos aprendizes se coloca como ponto fundamental para redirecionar os roteiros inicialmente lançados pelos professores.

O que se enfatiza nessa abordagem, segundo Paynter (1992), é uma visão de educação musical e não um método de ensino de música. Para o autor, "na verdade, esta é uma área em que os métodos devem ser esquecidos, porque são a antítese da mente criativa. Quando se descobre que se inventou um sistema para o ensino da composição, então é o momento de desistir dele." (Paynter, 1992, p. 30)

A abordagem de Paynter (1992) comunga de princípios que ressaltam a importância da improvisação ${ }^{4}$ e da composição na formação musical, em aulas desenvolvidas em escolas de ensino regular na Inglaterra. O educador afirmou ser possível construir música ou fragmentos de música a partir de uma atitude de

\footnotetext{
${ }^{4}$ Improvisação e composição são resultantes de processos criativos em música. Grosso modo, a improvisação possui características de efemeridade e a composição de permanência, como músicas originais, arranjos, e rearranjos das existentes. Os limites entre uma possibilidade e outra serão sempre contextuais.
} 
escuta ativa e experimental, dentro de um reino de possibilidades de descobertas e de jogos exploratórios em que os materiais são os condutores da criação de novos sons e a construção de propostas de criação sonora e musical. O resultado é a transformação da aula de música em oficinas de experimentação e criação musical.

$\mathrm{O}$ autor ressaltou que, apesar da grandeza de possibilidades para se fazer música, a educação musical continua voltada para o passado, ignorando essas possibilidades, como se elas não existissem, e segue considerando apenas os sons tradicionalmente empregados para se fazer música - as notas musicais, e pouco estimula a escuta e o uso de outros sons. $\mathrm{O}$ trabalho com o foco na escuta traz para o debate uma questão referente àquilo que existe de mais importante para essa área do conhecimento porque, segundo Favaretto (2012, p. 55), ao discorrer sobre o porquê da música na escola de educação básica no Brasil, afirmou:

A música me parece ser o único lugar em que se desenvolve um comportamento e uma atitude, que é a escuta. A escuta é uma experiência diferente da experiência do ouvir, que é do cotidiano, que é contido e provém da música a qualquer tipo de som e ruído. A escuta implica num tipo de atenção específica e tem tudo a ver com atenção e a concentração do pensamento. A relação final acaba sendo entre música e pensamento.

A proposta do educador inglês mencionado acima evidencia o quanto ele acreditava na capacidade criativa dos alunos das escolas nas quais trabalhou, e como os estimulava nesse caminho de invenção e da construção da própria experiência e do próprio conhecimento em música.

Koellreutter (1994), por sua vez, e de quem fui aluna, também construiu fundamentos interessantes para pensar a aprendizagem na área. Logo na minha primeira aula com o compositor, desafiou o grupo com o qual estava, afirmando que deveríamos sempre duvidar dos nossos professores, de nossos pais e até de nós mesmas. O currículo, por exemplo, segundo ele, poderia assumir um formato circular, sem necessariamente ter o mesmo ponto inicial para todo e qualquer grupo. Afirmou ainda que a prática musical deveria acontecer junto à reflexão intelectual, à pesquisa, à crítica e ao constante questionamento. Enfatizou que a aprendizagem deveria promover a ampliação da percepção e da consciência, a superação de preconceitos, a suplantação de posturas dualistas e individualistas e adotar um modo de ensinar e aprender no qual não se educa no sentido tradicional 
de inculcação de regras e condutas, mas que se conscientiza e orienta por meio dos diálogos e dos debates (Brito, 2011). Criou modelos de improvisação para serem usados em contextos diversificados e não apenas nos especialistas da área, e lembrava sempre que a improvisação musical é ferramenta pedagógica fundamental a ser muito bem planejada para não perder seu sentido e objetivos que, para o autor, suplantavam os de aprender música, e que acabam por envolver outras aprendizagens, inclusive de como melhor nos relacionarmos uns com os outros ao fazermos música juntos.

Delalande (2019, 2017, 1976, 1989) que fundamentou grandemente a condução de minha pesquisa de campo no doutorado (Cunha, 2017), investigou condutas musicais de bebês e de crianças bem pequenas, relacionando-as com aquelas que empregam músicos profissionais em suas performances, e afirmou que podem ser pensadas como as mesmas. Segundo o autor, um bebê, quando está diante de um objeto qualquer que soa, e um músico profissional, quando está às voltas com seu instrumento musical, aprimoram gestos em busca da sonoridade que mais lhes afeta ou que expresse melhor o que querem mostrar ao tocar. Para Brito (2007, p. 83), que estudou as ideias do autor para compreender melhor as crianças pequenas com as quais trabalha, nesse caso, o que muda é o nível de complexidade envolvido nessas ações de crianças e de adultos.

Com base nas ideias de Delalande (Cunha, 2017), propus, como resultado da pesquisa-ação desenvolvida no doutorado com professoras da educação infantil, que a atuação com bebês e crianças pequenas possa percorrer um caminho que abarca estímulos aos gestos produtores de sons, pois estes, de acordo com o autor, impactam a escuta e a partir desse momento passam a ser repetidos pois guiados pelos sons. Essas repetições, e também as variações nos modos de tocar que decorrem do ato inicial, podem resultar em ideias musicais, que são efeitos sonoros, pequenos temas ou motivos rítmicos e melódicos. Essas ideias, quando acolhidas e ampliadas pela ação docente planejada, podem conduzir às invenções musicais ao ecoá-las quando as repetem, quando propõem variações, diálogos de tocar, desdobramentos todos que podem levar as crianças a improvisar e até mesmo a realizar pequenas composições. 
O papel das professoras seria então o de acolher tais experimentações, estabelecer pequenas conversas ao repetir o que bebês e crianças pequenas realizam espontaneamente porque afetados pela escuta, por exemplo. Esse é um trabalho fundado na dupla escuta que, ao ser exercitada cada vez mais pelos adultos, acolhe e incentiva esses pequenos aprendizes a continuar sua relação com sons e músicas. Novas oportunidades podem ser criadas ao oferecer-lhes uma diversidade de instrumentos musicais, convencionais e não convencionais, trazer-lhes referências de músicas de autores de vários tempos, culturas e gêneros, ampliando escutas, adicionando outros saberes que, juntos, promovem a aquisição de conhecimento nesse campo artístico.

\section{quem aprende com quem? conversa final}

Caminhando para o final dessas conversas entre a educação musical e os estudos da infância, enfatizo a importância dessa junção de esforços interdisciplinares que ampliam conhecimentos, com a certeza de que estes se potencializam com as contribuições das abordagens pedagógicas criativas. Estas, por sua vez, são promotoras das escutas das crianças e tornam audíveis suas expressões musicais, nem sempre consideradas como legítimas, muitas vezes pensadas como barulhos e atrapalhação nas rotinas das escolas.

Nas experimentações de materiais e modos de fazer que privilegiam improvisações, composições, criação de novas roupagens para músicas de outros autores, outras possibilidades podem ser acrescidas e desdobradas dessas duas ações primeiras. Criação de trilhas sonoras, jogos, escritas inventadas e outras já existentes que desencadeiam reflexões, promovem defesas de ideias, negociações de pontos de vista. São situações que, ao mesmo tempo em que ensejam novas aquisições de saberes e de modos de fazer, hospedam, de modo afetivo, a participação infantil. Nas escolhas de caminhos feitos, em vez de metodologias de ensino nos quais todas as decisões, escolhas de caminhos e interesses são decididos somente pelos adultos, mostra-se mais pertinente a adoção de abordagens pedagógico-musicais com currículos abertos, em formatos não-lineares, não-causais e multidirecionais centrados na criação (Fonterrada, 2015). 
Ao ter como princípios norteadores a escuta ativa e a experiência inventiva, as abordagens criativas tomam rumos alternativos que podem ou não prescindir de sistemas hegemônicos de organização sonora, distanciar-se de suas normas estritas e impulsionar um fazer musical mais livre que, ainda que situado nas culturas de pertença de cada sujeito dessa relação educativa, aponta para vários modos de fazer música. Abre-se, assim, um mundo de realizações que desconhecem pré-conceitos, que se afasta dos certos e errados que constituem modelos já estabelecidos e reconhecidos pelas estéticas adultas. Em assim pensando, não são essas modelagens o que mais importa, nem seus resultados, e sim os processos de aquisição de conhecimento que se constroem nas relações entre adultos e crianças e entre crianças.

Tais propostas são, ademais, inclusivas por princípio, pois as singularidades de cada criança se revelam e se fortalecem enquanto expressão pessoal, aspecto que compõe, também, o trabalho com a arte. Essa pessoalidade expressiva vai se mostrando e pavimentando seus caminhos pelos interesses de cada uma delas que emerge das escolhas feitas e nos saberes que cada uma revela ao encontrar seus próprios modos e procedimentos para trabalhar o material e apresentar seus resultados, sejam eles efêmeros, transitórios ou mais permanentes.

Os interesses das crianças em saber mais pode ser questão norteadora das propostas, bem como o exercício e a construção da autonomia, a valorização do conhecimento musical e o engajamento nos processos de construção de conhecimento, tidos também como princípios fundantes. Os direitos das crianças e jovens entram na agenda das discussões em torno dos processos criativos na educação musical da infância, e trazem para o debate a questão dos seus direitos de participação.

Pela via da experiência artística, essas abordagens inventivas e colaborativas entre professores e crianças podem resultar em seres humanos mais autônomos, críticos, criativos, e que aprendem a trabalhar de modo cooperativo, pontos importantes e sobre os quais o campo da educação vem se debruçando nesse seu repensar de processos, abordagens, princípios e fundamentos, haja visto a crise em que ela se encontrava e que se agravou ainda mais nos últimos anos pelos impactos 
das atuais políticas públicas. Acredito que a educação musical, enquanto campo que dialoga com outros campos das artes e das ciências humanas, pode contribuir para esse debate ao também mostrar os caminhos potentes que as práticas musicais criativas têm exercitado, e que evidenciam como as crianças se engajam nesses fazeres e aprenderes, e podem servir também de inspiração para outras áreas do conhecimento, em contextos variados, da educação básica aos cursos livres.

Como ilustração de um trabalho dessa natureza, ressalto o que Kater (2017) vem desenvolvendo em escolas públicas das periferias de cidades brasileiras, e que acredito possa ser pensado como uma possibilidade de educação musical da infância brasileira. O projeto teve início em São Bernardo do Campo, São Paulo, e ganhou o nome de "A Música da Gente" 5 . O objetivo da proposta é o de que as crianças possam aprender música fazendo-a, por meio de criações musicais coletivas. Nesse intento, o autor enfatiza a pesquisa, a construção e o uso de instrumentos musicais não convencionais, regidos por princípios que chama de os cinco "ps": prazer de fazer música, qualidade da presença, participação, produção de conhecimento e mudança de postura face a esse trabalho que assume feições e escutas notadamente colaborativas que ampliam saberes em todos os aspectos.

Por último, mas com a intenção de que os diálogos continuem e se ampliem, destaco, ainda, a importância de serem realizadas pesquisas com essa temática dialogal, bem como a divulgação e discussão de seus contributos para os campos de conhecimento abordados nesse ensaio, porque as crianças têm muito a nos dizer com suas músicas. De modo especial, para professores e estudiosos da infância, esse conhecimento promove a ampliação da escuta das crianças ao saberem da relação potente que existe entre crianças e música. A importância da educação musical na escola pode vir como resultado alvissareiro.

\section{referências}

Arroyo, Margarete. Pensando a Educação Musical Imaginativamente: uma filosofia da educação musical por Estelle Ruth Jorgensen. Per Musi. Belo Horizonte, n. 27, 2013, p. 231-236.

\footnotetext{
${ }^{5}$ A música da gente. Para conhecer o projeto, acessar: https://www.carloskater.com.br/a-musicada-gente-2018; https://www.youtube.com/watch?v=AE9z1MCL9Ms
} 
<http://musica.ufmg.br/permusi/permusi/port/numeros/27/num27_cap_20.pdf> Acesso em 21 jan. 2020.

Arroyo, Margarete. Educação Musical na Contemporaneidade. In: II Seminário Nacional de Pesquisa em Música da UFG: Anais. Goiânia: Universidade Federal de Goiás, 2002, p. 1829. Disponível

em: <http:/ / www.musicaeeducacao.ufc.br/Para\%20o\%20site/Revistas\%20e\%20peri\%C3 \%B3dicos/Educa\%C3\%A7\%C3\%A3o\%20Musical/Ed\%20Mus\%20contemporaneidade \%20Arroyo.pdf > Acesso em: 22 jan. 2020.

Brito, Maria Teresa Alencar de. Por uma Educação Musical do Pensamento: novas estratégias de comunicação. 2007. 288 p. Tese (Doutorado em Comunicação e Semiótica). PUC-SP. São Paulo.

Brito, Teca Alencar de. Koellreutter Educador: o humano como objetivo da educação musical. São Paulo: Peirópolis, 2011.

Corsaro, William. Sociologia da Infância. Porto Alegre: Artmed, 2011.

Cunha, Sandra Mara da. Crianças na Congada de Santa Efigênia: aprendizagens e saberes intergeracionais. (Relatório de Pós-doutorado). São Paulo, FEUSP, 2018.

Cunha, Sandra Mara da Eu Canto Pra Você: saberes musicais de professores da pequena infância. Curitiba: CRV, 2017.

Cunha, Sandra Mara da. Música e crianças em diálogo: contribuições da sociologia da infância. (Actas) I Colóquio Internacional de Ciências Sociais da Educação/III Encontro de Sociologia da Educação. Universidade do Minho, Braga, vol. 3, p. 1445-1452, 2013. Disponível em: <https://www.academia.edu/23741729/M\%C3\%BAsica_e_crian\%C3\%A7as_em_di\% C3\%A1logo_Contribui\%C3\%A7\%C3\%B5es_da_sociologia_da_inf\%C3\%A2ncia> Acesso em 30 jan. 2020.

Delalande, François. A Música é um Jogo de Criança. São Paulo: Peirópolis, 2019.

Delalande, François. Pedagogia da criação musical hoje: partir da infância, passar pela adolescência e ir além. Orfeu, v.2, n.2, 2017, p. 13-30. Disponível em: <http://www.revistas.udesc.br/index.php/orfeu/article/view/1059652525530402022 017013> Acesso em 28 jan. 2020.

Delalande, François. Trois idées-clés pour une pédagogie musicale d'éveil. Pédagogie musicale d'éveil, Cahiers recherche/musique n¹ INA/GRM, Paris, 1976. Disponível em: $<$ http://www.francois-delalande.fr/publications/ordrechronologique/téléchargements-70/> Acesso em 28 jan. 2020.

Delalande, François. El rol de los dispositivos en una pedagogía de la creación musical infantil. François Delalande, Responsable de las investigaciones teóricas, INA-GRM, París - Francia. Traducción: María Guadalupe Segalerba, 1989. Disponível em: <http://www.francoisdelalande.fr/publications/classement-par-domaines/téléch-trad-inédites/> Acesso em: 28 jan. 2020.

Eliasson, Olafur. Artworks: Studio Olafur Eliasson. Disponível em: $<$ https://olafureliasson.net/archive/artwork> Acesso em 06 fev. 2020

Favaretto, Celso. Música na Escola: por que estudar música? In: Jordão, Giselle; Allucci, Renata; Molina, Sergio; Terahata, Adriana Miritello. A Música na Escola. São Paulo: Alucci \& Associados Comunicações, 2012, p. 46-48.

Fidalgo, Zilda. Psicologia Cultural e Desenvolvimento Humano: um encontro com Barbara Rogoff. Análise Psicológica 2004, 1 (XXII): p. 7-9.

Fonterrada, Marisa Trench de Oliveira. Ciranda de Sons: práticas criativas em educação musical. São Paulo: UNESP, 2015.

Freire, Paulo. Pedagogia da Autonomia: saberes necessários à prática educativa. Ano da publicação original: 1996; ano da digitalização: 2002. Disponível em: <www.sabotagem.revolt.org> Acesso em: 28 jan. 2020. 
Holm, Anna Marie. Baby-Art: os primeiros passos com a arte. São Paulo: Museu de Arte Moderna de São Paulo - MAM, 2007.

Kater, Carlos. "A Música da Gente: contribuições para um educação musical hoje”. Palestra de abertura do IX Encontro de Pesquisa do MusE - Grupo Música e Educação. Florianópolis: CEART/UDESC, 09 a 11 de Agosto de 2019.

Koellreutter, Hans-Joachim. O Objetivo da Educação Musical: o humano. (Texto original do autor para seus cursos de formação). São Paulo, 1994.

Kohan, Walter. A escola como experiência: entrevista com Walter Omar Kohan. Revista Eletrônica de Educação, v. 12, n. 1, 2018, p. 298-304. Disponível em: <http://www.reveduc.ufscar.br/index.php/reveduc/article/view/2297/685> Acesso em 24 jan. 2020.

Kohan, Walter. Visões de filosofia: infância. ALEA. Rio de Janeiro, vol. 17, n. 2, p. 216-226, 2015. Disponível em: <http://www.scielo.br/pdf/alea/v17n2/1517-106X-alea-17-0200216.pdf> Acesso em 24 jan. 2020.

Lino, Dulcimarta Lemos. Barulhar: a escuta sensível da música nas culturas da infância. (Tese). Doutorado em Educação. UFRGS, 2008.

Paynter, John. Sound \& Structure. New York: Cambridge University Press, 1992.

Prout, Alan. The Future of Childhood: towards the interdisciplinary study of children. New York: Routledge Falmer: 2005.

Richter, Sandra Regina Simonis. Crianças Pintando: experiência lúdica com as cores. Cunha, Susana Rangel Vieira da (org.) As Artes no Universo Infantil. $2^{\text {a }}$ ed. Porto Alegre: Mediação, 2012, p. 59-107.

Sarmento, Manuel Jacinto. As Culturas da Infância nas Encruzilhadas da $2^{a}$ Modernidade. CEDIC Centro de Documentação e Informação Sobre a Criança. Centro de Estudos da Criança, Universidade do $2002 . \quad$ Disponível em: <http://cedic.iec.uminho.pt/Textos_de_Trabalho/menu_base_text_trab.htm> Acesso em: 27 jan. 2020.

Sarmento, Manuel Jacinto. Imaginários e Culturas da Infância. CEDIC - Centro de Documentação e Informação Sobre a Criança. Centro de Estudos da Criança, Universidade do Minho, $2003 . \quad$ Disponível em: <http://cedic.iec.uminho.pt/Textos_de_Trabalho/textos/ImaCultInfancia.pdf> Acesso em: 25 jan. 2020.

Schafer, Murray. O Ouvido Pensante. São Paulo: Fundação Unesp, 1991.

Shiota, Chiharu. Website oficial. Disponível em: <https://www.chiharu-shiota.com/top>. Acesso em 06 fev. 2020.

Soares, Natália Fernandes. Os Direitos das Crianças nas Encruzilhadas da Protecção e da Participação. Zero-a-Seis, n. 12, 2005. Disponível em: $<$ https://periodicos.ufsc.br/index.php/zeroseis/article/view/2100> Acesso em 25 jan. 2020.

Spinoza. Ética. Belo Horizonte: Autêntica, 2018.

Tadeu, Tomaz. A arte do encontro e da composição: Spinoza + currículo + Deleuze. Educação e Realidade, vol. 27, n. 2, 2002, p. Disponível em: <https://seer.ufrgs.br/educacaoerealidade/article/view/25915> Acesso em 31 jan. 2020. 